\title{
Autorité, agents de l'autorité et pratiques du pouvoir au Moyen Âge
}

Dijon, 2 avril 2010

\section{Bruno Lemesle}

\section{OpenEdition}

Journals

\section{Édition électronique}

URL : https://journals.openedition.org/cem/11978

DOI : $10.4000 /$ cem. 11978

ISSN : 1954-3093

Éditeur

Centre d'études médiévales Saint-Germain d'Auxerre

Édition imprimée

Pagination : 223-224

ISSN : 1623-5770

\section{Référence électronique}

Bruno Lemesle, "Autorité, agents de l'autorité et pratiques du pouvoir au Moyen Âge », Bulletin du centre d'études médiévales d'Auxerre / BUCEMA [En ligne], 15 | 2011, mis en ligne le 22 août 2011, consulté le 22 septembre 2022. URL : http://journals.openedition.org/cem/11978 ; DOI : https:// doi.org/10.4000/cem. 11978

Ce document a été généré automatiquement le 22 septembre 2022.

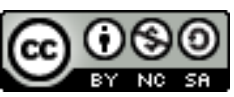

Creative Commons - Attribution - Pas d'Utilisation Commerciale - Partage dans les Mêmes Conditions 4.0 International - CC BY-NC-SA 4.0

https://creativecommons.org/licenses/by-nc-sa/4.0/ 


\section{Autorité, agents de l'autorité et pratiques du pouvoir au Moyen Âge}

Dijon, 2 avril 2010

\section{Bruno Lemesle}

1 Le thème de cette journée d'études a été choisi dans la perspective de l'un des axes de notre centre de recherches, intitulé «organisation sociale ; rapport de dépendances, organisation et hiérarchies sociales ", afin de lui offrir un développement. Les agents de l'autorité participent, en effet, à l'organisation sociale, dont ils sont une articulation grâce à leur position entre ceux qui détiennent l'autorité et le corps social. L'autre raison pour les évoquer, qui, bien entendu, est la principale, est l'intérêt qu'ils suscitent dans l'historiographie actuelle: nous le voyons à travers les ouvrages qui consacrent une de leurs parties à ces agents et surtout aux ouvrages ou articles qui leur sont spécifiquement consacrés ${ }^{1}$.

2 L'expression « agents du pouvoir ", à travers le vaste Moyen Âge, recouvre des termes évidemment très différents et des fonctions encore plus différentes, selon qu'on se situe sur le versant du haut Moyen Âge, où, en dépit de l'âge carolingien, il n'existe pas d'État authentique, et le versant où l'État se construit, soit à partir du XII ${ }^{e}$ siècle. Selon que l'on évoque les avoués des temps mérovingiens et carolingiens, les prévôts et les viguiers, les prévôts $\mathrm{du} \mathrm{xI}^{\mathrm{e}}$ siècle étant eux-mêmes très différents de leurs successeurs des derniers siècles du Moyen Âge, ou encore les vicomtes, les maires, les sénéchaux, les baillis et les lieutenants généraux, pour ne citer que les principaux, nous avons affaire à des personnes et à des fonctions dotées de leur spécificité et de leurs caractéristiques propres, mais qui ont cependant en commun de participer à l'exercice du pouvoir, tout en étant généralement investies par une autorité.

3 L'intérêt que ces agents suscitent actuellement est la conséquence de ce qu'ils ont longtemps été peu étudiés, le plus souvent faute de documents ou parce que ces documents n'offrent que des informations dispersées, donc plus difficiles à appréhender et à synthétiser. Pour ne prendre que l'exemple de la justice, les praticiens ont ainsi été relégués derrière les termes qui les désignent, les conflits de compétence juridictionnelle, voire les procédures. 
4 Dans la période centrale du Moyen Âge, si les historiens ont, depuis longtemps, consacré des travaux à la construction politique et à la fraction la plus élevée de la société - les princes, les seigneurs, les chevaliers -, les personnes de rang inférieur ont fait l'objet d'approches seulement partielles. L'historiographie ancienne s'est surtout intéressée aux fonctions, en s'attachant à les décrire et à les différencier, et, dans une moindre mesure, à établir des notices sur les personnages les plus importants. Toutefois, elle ne s'est guère préoccupée de leur insertion dans des réseaux de pouvoir et n'a pas évoqué leur rôle dans les conflits et dans les luttes politiques. Elle s'est, en revanche, un peu intéressée à leur recrutement et à leur carrière, ce qui a permis aux recherches récentes de renouveler les conclusions ${ }^{2}$.

5 Ces personnes de rang moins élevé exigent pourtant toute notre attention, puisque c'est en grande partie à travers elles que les pouvoirs s'exercent. D'ailleurs, les documents de la pratique, à peu de chose près les seuls qui nous renseignent sur elles, les présentent souvent comme acteurs et même comme la cause des nombreux litiges qui les opposent aux établissements religieux. En revanche, nous percevons moins bien leur rôle dans les conflits de grande envergure, notamment dans les conflits politiques, car, bien que des indications existent, elles sont dispersées.

Le titre de l'un des ouvrages collectifs cités indique une approche parmi bien d'autres, mais fort importante : le contrôle des agents. Le contrôle repose sur l'idée des abus qu'ils commettent ou sont susceptibles de commettre. Par ailleurs, nous savons qu'une réflexion sur la nécessité pour le prince de contrôler ses agents s'élabore au XII siècle, période qui coïncide avec celle où s'étoffent les administrations princières et royale. Sous d'autres aspects et dans des conditions différentes, cette question s'est aussi posée au haut Moyen Âge autour des avoués, par exemple. Cependant, la lutte contre les abus de pouvoir a surtout été le fait de l'État, puisque, pour nous limiter au royaume de France, c'est avec la mise en place des baillis par Philippe Auguste, dès 1184, qu'elle est parallèlement mise en œuvre et qu'elle devient, du moins selon une historiographie ancienne qu'il importe de rafraîchir - ce qui est en cours -, l'une des préoccupations des souverains : nous pensons évidemment à Louis IX et aux fameuses enquêtes de 1247-1248.

7 Il est nécessaire d'indiquer cette piste en raison de son importance et parce qu'elle ouvre sur quantité d'autres aspects, qui ne peuvent pas être abordés dans leur totalité. Parmi les autres angles d'approche possibles, nous pouvons retenir: le choix des agents, leur mode de désignation, leur origine sociale ; les carrières qu'ils effectuent ; leur insertion dans les réseaux de pouvoir et, bien sûr, la question cruciale de leur rôle dans les relations de pouvoir, entre pouvoir princier et pouvoirs locaux, et entre pouvoir royal et pouvoir ecclésiastique, en particulier; l'idéologie et les conceptions qui sous-tendent leur action ; leur formation intellectuelle, etc.

8 Cette journée avait donc pour but d'offrir quelques approches des travaux en cours sur cette question. 


\section{NOTES}

1. Citons à titre indicatif: L. FELLER (dir.), Contrôler les agents du pouvoir, Limoges, 2004 ; D. BARTHÉLEMY et O. BRUAND (dir.), Les pouvoirs locaux dans la France du centre et de l'ouest (vIII e $_{-}$ $\mathrm{XI}^{\mathrm{e}}$ siècle). Implantation et moyens d'action, Rennes, 2004 ; O. MATTÉONI, Servir le prince. Les officiers des ducs de Bourbon à la fin du Moyen Âge (1356-1523), Paris, 1998 ; W. PARAVICINI et K. F. WERNER (dir.), Histoire comparée de l'administration ( $\mathrm{IV}^{\mathrm{e}}$-XVIII ${ }^{\mathrm{e}}$ siècle), Munich, 1980 ; R. TELLIEZ, Per potentiam officii. Les officiers devant la justice dans le royaume de France au XIV ${ }^{e}$ siècle, Paris, 2005.

2. W. PARAVICINI et K. F. WERNER (dir.), Histoire..., ibid.

\section{INDEX}

Mots-clés : autorité, pratique du pouvoir 